\title{
Correction to: Odontogenic keratocyst and ameloblastoma: radiographic evaluation
}

\author{
Jira Kitisubkanchana ${ }^{1}\left[\right.$ - Nor Hidayah Reduwan ${ }^{2} \cdot$ Sopee Poomsawat ${ }^{3} \cdot$ Suchaya Pornprasertsuk-Damrongsri ${ }^{1}$. \\ Chanchai Wongchuensoontorn ${ }^{4}$
}

Published online: 7 July 2021

๑ Japanese Society for Oral and Maxillofacial Radiology and Springer Nature Singapore Pte Ltd. 2021

\section{Correction to: Oral Radiology (2021) 37:55-65 \\ https://doi.org/10.1007/s11282-020-00425-2}

In the original publication of the article, the following two papers are missing from Table 4 and Table 5, and should be added to the references.

40. MacDonald-Jankowski DS. Keratocystic odontogenic tumour: systematic review. Dentomaxillofac Radiol. 2011;40(1):1-23.

41. MacDonald-Jankowski DS, Yeung R, Lee KM, Li TK. Ameloblastoma in the Hong Kong Chinese. Part 2: systematic review and radiological presentation. Dentomaxillofac Radiol. 2004;33(3):141-51.

The correct Tables 4 and 5 are given in this correction.

Publisher's Note Springer Nature remains neutral with regard to jurisdictional claims in published maps and institutional affiliations.

The original article can be found online at https://doi.org/10.1007/ s11282-020-00425-2.

Jira Kitisubkanchana

yjira@hotmail.com

1 Department of Oral and Maxillofacial Radiology, Faculty of Dentistry, Mahidol University, No. 6, Yothi Road, Ratchathewi District, Bangkok 10400, Thailand

2 Faculty of Dentistry, Centre of Oral and Maxillofacial Diagnostic and Medicine Studies, Universiti Teknologi Mara, Sungai Buloh Campus, Shah Alam, Malaysia

3 Department of Oral and Maxillofacial Pathology, Faculty of Dentistry, Mahidol University, Bangkok, Thailand

4 Department of Surgery and Oral Medicine, Faculty of Dentistry, Srinakharinwirot University, Bangkok, Thailand 


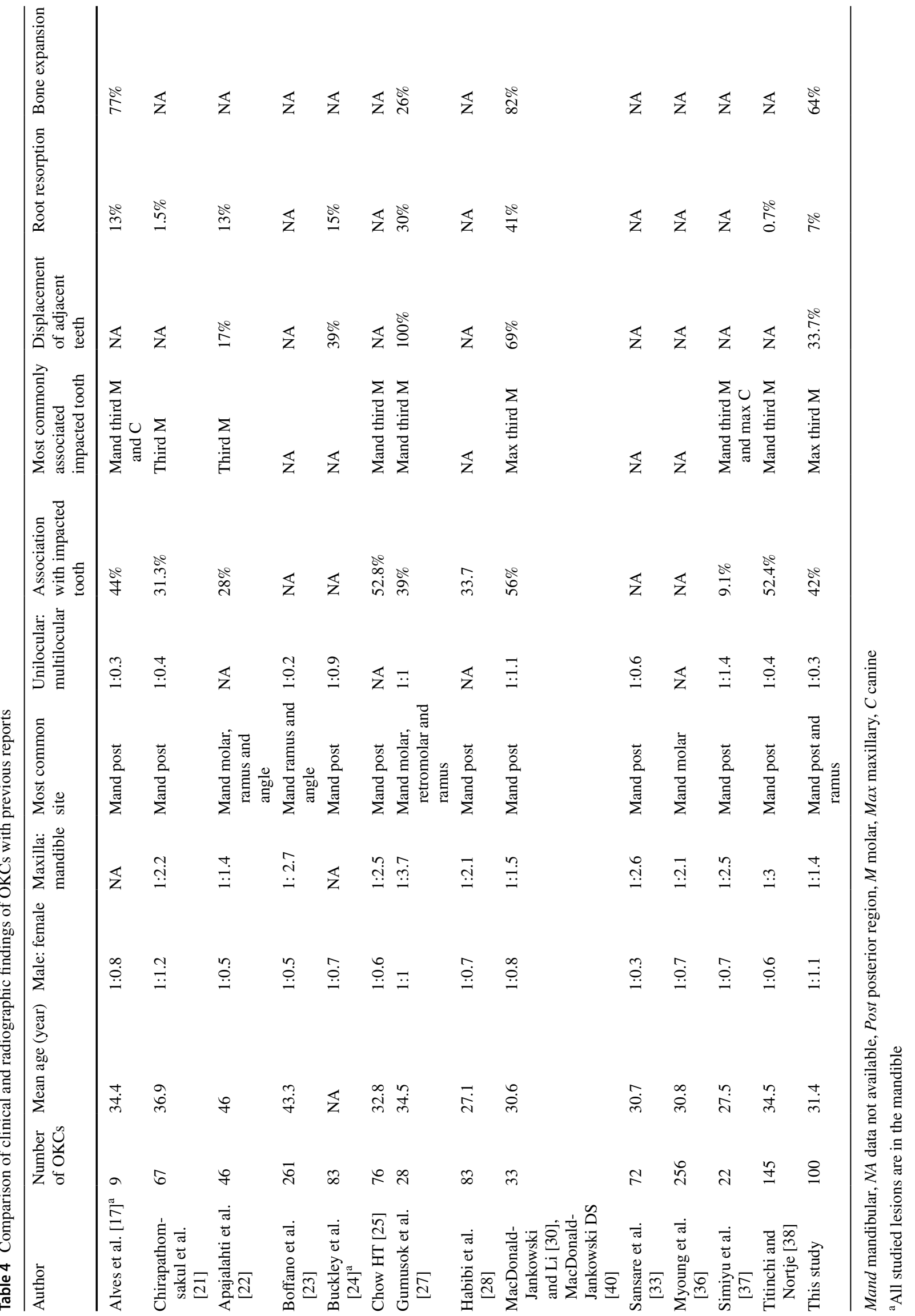




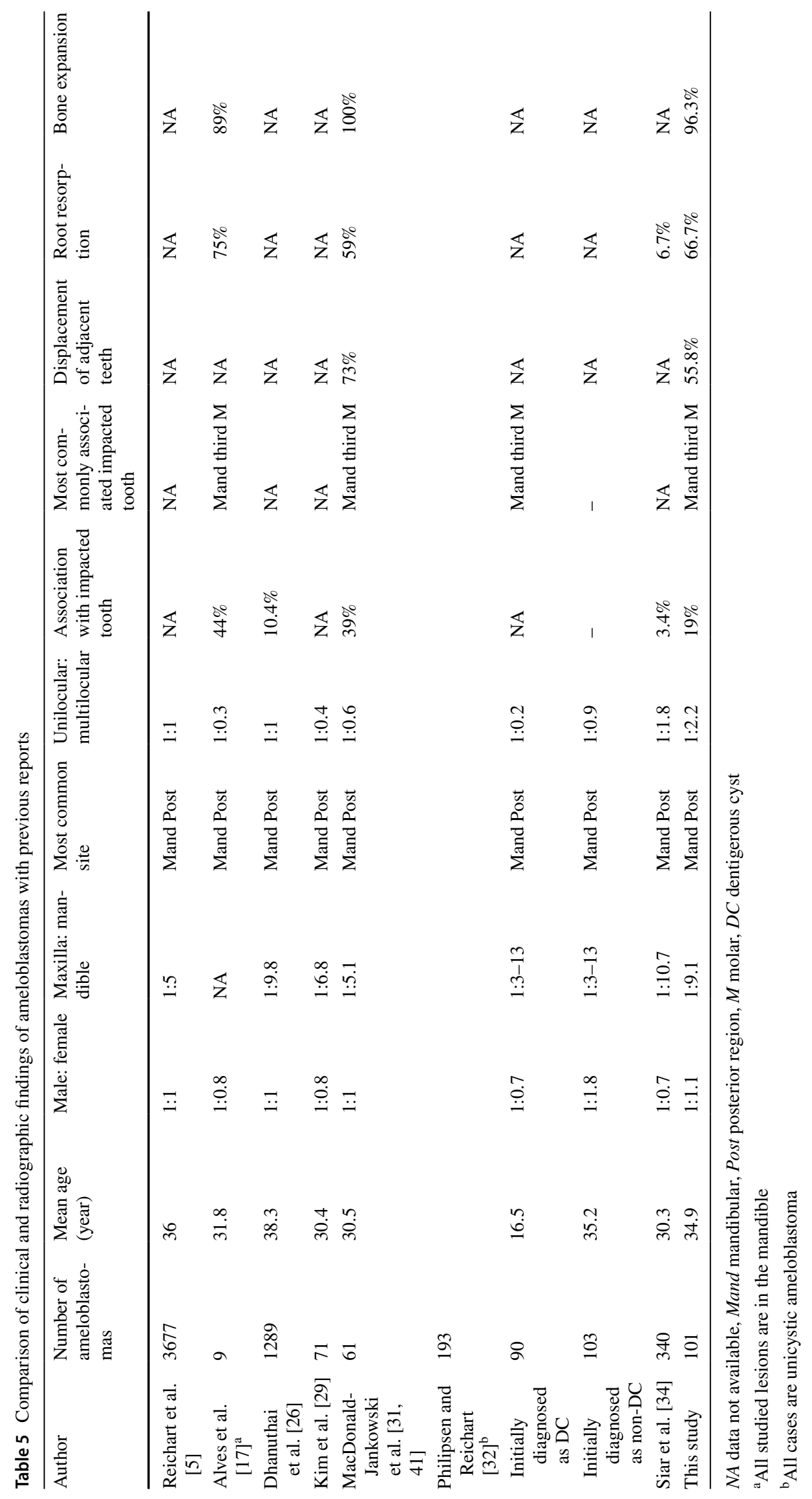

